\title{
EL DERECHO Y LA NATURALEZA DE LAS COSAS
}

\author{
"Tenemos que escuchar a las cosas an- \\ tes de disponernos a ordenarlas". \\ Franza Böhm.
}

\section{Retorno del hombre hacia las cosas}

El retorno del hombre hacia las cosas, para descubrir en ellas el sentido de sus creaciones y de sus instituciones, constituye una actitud general en nuestra época que se manifiesta a través de diversos aspectos de la vida y de la cullura.

Varios siglos de racionalismo determinaron un inmenso desarrollo teórico y la formación de estructuras intelectuales que nos han ido alejando cada vez más del mundo de lo concreto.

La reacción ha surgido tanto en la poesía como en la literatura, tanto en la filosofía como en el derecho.

"Para encontrar la esencia del arte, que realmente está en la obra -dice Heidegger en su bello ensayo sobre "Arte y Poesia" - busquemos la obra real y preguntémosle qué es y cómo es". La belleza de la obra es un modo de ser de la verdad que refleja el objeto (1).

En literatura "la vuelta a la realidad es un fenómeno universal". Frente a las cosas del mundo, el escritor manifiesta "alienación" o "extrañamiento" (Brecht), "alteración de sus contactos con el mundo" (Camus, Hemingway), "abandono" en medio de una realidad hostil (Kafka) o confusión de lo ideal y 10 real (Borges, Broch) (2).

1. Trad. de Samuel Ramos. Fondo de Cultura Económica. México, pg. 32.

2. "La naturaleza de las cosas como forma del pensamiento jurídico", por G. Radbruch. Versión española de Emesto Garzón Valdés. Universidad de Córdova, 1963. Introducción de Ernesto Garzón Valdés, pg. 23.
Por su parte, la filosofia existencial presenta al hombre rodeado de un universo de cosas que tiene "a mano" para su utilidad y servicio.

En el ámbito del derecho se ha realizado el mismo fenómeno. Recusados los fundamentos teológicos del orden jurídico después de la Reforma, se buscó para aquél un afianzamiento racional constituido por normas universales y apriorísíicas de las que se pretendía deducir todo el sistema jurídico (3).

La esterilidad de tal actitud ha sido la causa determinante del anhelo profundo de diversos sectores del pensamiento en nuesira época que buscan acercarse al mundo de las cosas (4).

\section{El problema de la naturaleza de las cosas en la historia del pensamiento jurídico}

Fueron los juristas romanos -a través de la jurisprudencia - quienes afirmaron con mayor claridad la relación entre el derecho y las cosas.

Los antecedentes de la docirina sobre la "naturaleza de las cosas" se hallan en el poema didáctico de Lucrecio, para quien "rerum natura" equivalía a "legalidad universal"'.

Ulpiano llamó a la Jurisprudencia "rerum notitia" (estudio de las cosas); Gayo fundó su experiencia en el examen de las "res" (cosas). Para el Digesto "rerum natura" significa: universo, curso del mundo y naturaleza de las cosas (5).

Para Cicerón una "raîio profecta a rerum natura" es la regla racional suprema ínsita en la "naturaleza

3. Henri Batiffol. Philosophie du Droit. Presses universitaires de France, pg. 68.

4. Batiffol, ob. cit., pg. 57.

5. Radbruch ob. cit., pg. 90. 
de las cosas" (6), y el entendimiento existe en el mundo $y$ en el cielo, y no es patrimonio exclusivo de la mente humana como cree la arrogancia de los necios (7).

Para el pensamiento jurídico de Santo Tomás, inspirado en Aristóteles, el derecho natural se sustenta en la naturaleza del hombre y del mundo y es reflejo del orden impuesto por Dios al Universo. La justicia es la virtud ordenadora por excelencia, tiende a ubicar a los hombres y a los procesos sociales en el rango que les corresponde en la eterna jerarquia del ser.

En cuanto a la aplicación de las normas, los principios primeros llegan a los casos concretos en virtud de los procedimientos de deducción y determinación.

El jurista debe tener siempre presentes las particularidades de los diversos casos, esto es, "la naturaleza de las cosas". La misma regla no puede aplicarse del mismo modo a dos situaciones diferentes. Es, por ejemplo, una norma general, la que obliga al depositario a devolver a su propieiario el objeto recibido en depósito, pero esa regla no puede aplicarse cuando el propietario del objeto - un arma- ha perdido la razón.

En la edad moderna, la filosofía copernicana de Kant, alejó al Derecho Natural del mundo de 10 concreto, al buscar sus fundamentos en la razón del hombre. Los continuadores de Kant deserivolvieron esa tesis hasta llegar a la posición idealista objetiva de Hegel.

Según esta posisión es el hombre y no los objetos el punto de partida del ordenamiento del mundo.

Moniesquieu en su obra "El espiritu de las leyes" asume una nueva posición. Las leyes, en su significación más amplia, nos dice, son "las relaciones necesarias que derivan de la naturaleza de las cosas".

Las leyes reconocen como fuentes y se aplican en base a la gran variedad de los hechos del mundo: hechos naturales tales como el clima, las condiciones del suelo, la situación y la extensión del país; hechos sociales, entre los que deben ser considerados las formas de vida (cazador, pastor, propietario, comerciante) número de habitantes, economía, usos, cos-

6. Cit. por Radbruch.

7. Id. pg. 92 . tumbres, tendencias, religión; hechos estatales y juridicos, tales como las formas del gobierno, objetivos del legislador, grados de libertad del individuo; y "orden de las cosas" esto es: leyes religiosas y laicas.

La inducción, que reemplazó a la deducción a partir de principios preconcebidos, por un procedimiento que desde los hechos se eleve a la construcción de los órdenes estatales y' jurídicos, "preparó el camino de la escuela histórica del derecho y de la ciencia del derecho comparado" (8).

Savigny subrayó el valor de la "naturaleza de las cosas" como método para resolver los conflictos de derecho internacional privado. La separación de las relaciones juridicas en cuanto conciernen a las personas, a los bienes y a los contrałos, ayudó a resolver los problemas sobre la aplicación territorial de la ley y a organizar la coexistencia de sistemas.

Savigny, ofrece además un aspecto nuevo de la naturaleza de las cosas, que no significa aquel "cuadro físico de las sociedades humanas" que imaginó Montesquieu, sino algo más complejo, "el conjunto de las relaciones de derecho" (Э).

Darburg fue quien definió con precisión más lograda el concepto de "naturaleza de las cosas". "Las relaciones vitales, dijo, llevan en sí mismas, más o menos desarrolladas, su medida y su orden'. $Y$, agregó: "ese orden inmanente de las cosas, es llamado naturaleza de la cosa. A ella tiene que volver el jurista reflexivo cuando carece de una norma positiva o cuando ésta es incompleta o confusa" (10).

Entre los tratadistas de los últimos aĩos de la pasada centuria y de comienzos de la presente, fue Francois Geny, el que trató con mayor acierto sobre el problema.

Al examinar Geny las fuentes formales del derecho, con el propósito de subrayar la importancia del método de la libre investigación cientifica, sostuvo que "es absolutamente erróneo creer que toda regla jurídica debe converger alrededor de una concepción ideal, inspirando la acción y determinando su alcance. Por lo contrario, prosigue, yo considero como a priori inconiestable que los más firmes y seguros preceptos de derecho son los que se desprenden direc-

8. Id. pg. 94 .

9. Annales de la Faculté du Droit de Toulouse. Tome XII. Fascicule I., pg. 94.

10. Cit. por Radbruch pg. 94. 
tamente de la naturaleza de las cosas, sin el intermediario de una concepción ideal que deforma siempre, de algún modo, las realidades" (11).

A la "naturaleza de las cosas", considerada como "fuente de derecho positivo" debe orientarse toda investigación juridica, porque "las relaciones de la vida social, o más generalmente, los elementos de hecho de toda organización jurídica (a lo menos posible) llevan en si las condiciones de su equilibrio y descubren, por decirlo así, ellas mismas, las normas que deben regirlas" (12).

El jurista tiene el deber de interrogar a su razón y a su conciencia para encontrar en ellas las bases mismas de la injusticia; pero debe recurrir también "a la naturaleza de las cosas positivas" que forman una especie de "atmósfera de la vida juridica exterior" (13).

En el coloquio realizado bajo los auspicios de la Universidad de Toulouse, en setiembre de 1964, sobre "La naturaleza de las cosas", Norberto Bobbio, recorció que los tratadistas italianos de Derecho Comercial de fines del siglo anterior, inspirados en la doctrina alemana, reconocieron la importancia de esa institución como fuente, en dicha rama del derecho.

Cesare Vivante en su "Tratatto di Diritto Commerciale" declaró que "cuando la regla aparece inmediatamente de la naturaleza de los hechos, debe dirigir el juicio de los jueces aurique no aparezca ni en la ley ni en la costumbre". Recordaba Vivante que "de esta naturaleza de las cosas... se alimentó continuamente el derecho civil de Roma" y que "la primera regla de toda construcción jurídica es la observación natural de los hechos" (14).

Sin embargo, otros especialistas en la misma disciplina, como Alfredo Rocco y Antonio Scialoja, recusaron la tesis de Vivante, excluyendo que se pueda admitir más fuentes que la ley y la doctrina, para calificar a la naturaleza de las cosas como medio de interpretación.

Al analizar Del Vecchio el problema de los principios generales del derecho, consideró que estos no

11. Francois Geny. Método de Interpretación y Fuentes en Derecho Privado Positivo. 2a edición. Ed. Reus. Madrid, 1925, pg. 532.

12. Geny, ob. cit. pg. 535 .

13. Id. pg., 539 .

14. Annales cit. pg, 197. son suficientes para colmar las lagunas, de donde deriva la necesidad de una fuente última que no puede ser otra que la "naturaleza de las cosas". De la opinión de Del Vecchio, derivó una interesante polémica en la que tomó parte activa el positivismo (15).

En el Congreso realizado en Saarbrüch en 1957, el propio Bobbio presentó una ponencia titulada "Die Natur des Sache" que ratificó en el certamen de Touluse.

Según Bobbio, "naturaleza de las cosas es una noción vaga que no ha sido analizada hasta el presente, mediante un examen amplio y escrupuloso de los textos de la jurisprudencia y de la doctrina en que se propicia su empleo" (16).

Sintetiza el citado autor su punto de vista sobre el problema de las siguientes conclusiones: "Primera.Recurrir a la naturaleza de las cosas no difiere de de la interpretación teleológica; y segunda.- El argumento teleológico, fundado sobre la relación mediofin, sirve para indicar los medios necesarios para realizar un fin en el caso en que el fin es dado, pero no sirve para establecerlo, lo que se obtiene exclusivamente de un juicio de valor" (17).

Las posteriores elaboraciones sobre la "naturaleza de las cosas", en sus aspectos ontológico y metodológico, según Maihofer, corresponden a los puntos de vista de la teoría apriorística del derecho de A. Reinach y de la teoría axiológica de G. Radbruc (18).

Según Reinach, los conceptos jurídicos tienen esencia y existencia, eternamente válidas, e independientes tanto del pensamiento humano, como del derecho positivo, análogas a las de los números matemáticos. La "naturaleza de las cosas" "es el conjunto de las leyes apriorísticas que constituyen la esencia de cada concepto jurídico" (19).

El análisis de dichas leyes apriorísticas nos lleva a considerarlas como "complejidades esenciales" que se encuentran en un estado de "conexión esencial".

De tal concepción surge una grave antinomia metodológica. O las esencias jurídicas son inmanentes a

15. Id.

16. Id. pg., 204.

17. Id. pg., 207.

18. M. Maihofer. Derecho y naturaleza de las cosas en la filosofía alemana del Derecho. Annales cit. pg., 110.

19. Id 
las cosas, y pueden ser aprehendidas, por abstracción y generalización, en cuyo caso el carácter apriorístico que se les atribuye significa una petitio principii; o son seres trascendentes, hipostasiados, en cuyo caso no podria explicarse su relación con el mundo real.

La relación entre hecho y valor origina una dificultad aún más ardua. Reinach piensa que las estruc. turas ontológicas del derecho no pueden dejar de ser valiosas - los valores juridicos se confunden con tales estructuras ontológicas- pero que la norma jurídica que señala un mandato para un caso determinado es independiente de su estructura ontológica.

El mérito de Reinach ha sido, sin embargo, demostrar la existencia de un derecho apriori distinto del derecho natural y que la noción de "naturaleza de las cosas" no se reduce a un derecho naturalmente inscrito en el corazón del hombre" (20).

El relativismo axiológico que Radbruch acentuó en la primera etapa de su pensamiento sufrió un cambio notable después de la segunda guerra. En el primer período, sostuvo Radbruch que el concepto de derecho apunta hacia la justicia, idea del derecho, que es un valor "formal" cuyo contenido proviene de otros valores.

En su estudio sobre "la naturaleza de las cosas como forma del pensamiento juridico", que data de 1948, Radbruch define tal concepto como "la significación de una relación vital de una idea de derecho", o más claramente aún como "la normatividad realizada en la facticidad" o "el valor en tanto que aparece en la real:dad".

La "relación vital vinculada a la idea de derecho" no es un ente pero si algo "vinculado a un ente" como "el sentido que corresponde a una relación vital fáctica, la expresión de una idea de derecho que se encuentra en la base de ese sentido" (21).

Para la concepción comentada, la idea de derecho lleva como elemento connotante su fundamento axiológico, con lo cual queda destruida la separación entre el "sein" y el "sollen" y entre la experiencia del objeto y la experiencia del valor (22).

20. Albert Brimo. Les grands courants de la Philosophie du Droit el de l'Etat. Editions A. Pedone. París, 1968. pg., 381.

21. Radbruch, ob. cit. pg., 78 .

22. Maihofer, pg., 127.
En cuanto a sus alcances, en la naturaleza de las cosas, según Radbruch, se sustenta "el pensamiento jurídico histórico, nacional y conservador" (23) y, en lo que atañe a su aplicación, no se trata de "algo que valga por sí mismo" o sea "fuente alguna de derecho" sino de la "ultima ratio de la interpretación y de la complementación de la ley" (24).

La filosofía existencialista del derecho, en orden al problema de la "naturaleza de las cosas", pretende, derivar su existencia de la vida social del hombre y confundir "hecho" y "valor".

En su análisis sobre los fundamentos de una "teoría antropológica de las situaciones jurídicas" Maihofer identifica la "naturaleza de las cosas" con la existencia y la conciencia social que se interpenetran en tanto que "conexiones indisolubles subjetivo-objetivas" (25). Las significaciones y los valores son productos y reflejos de la conciencia social de un sujeto como integrante de un complejo inter-subjetivo.

La experiencia existencia adquiere su sentido normativo de los principios formales de "universalidad" y "reciprocidad" que no justifican por sí solos ninguna valoración.

Según E. Fechner, otro jusfilósofo eminente de nuestro tiempo, los factores que intervienen en la formación del derecho son de dos tipos: factores reales (biológicos, económicos y políticos) y factores ideales (razón, valores y sentimientos religiosos).

Los factores reales constituyen el ámbito de la facticidad y son independientes de la libertad humana, que prolonga a través de los factores ideales las soluciones jurídicas esbozadas en el campo de los hechos y se erige en norma de derecho. La "naturaleza de las cosas" constituye el punto de encuentro entre los factores reales y los ideales, entre la facticidad y la libertad.

La trascendencia de los valores se revela por una relación existencial. El hombre no crea el valor, lo descubre y al descubrinlo participa en la creación total del ser del cual forma parte.

El derecho natural, según Fechner, es obra de la creación continua del hombre en base a la "naturaleza de las cosas" en su tarea de realizar los facto-

23. Radbruch, pg., 67.

24. Id. pg., 79 .

25. Annales, pg., 129. 
res ideales cuyos valores actualizan las posibilidades de la realidad factual (26).

El más penetrante análisis realizado en estos últimos años sobre "la naturaleza de las cosas" en el derecho, corresponde a Helmut Coing.

El concepto de "naturaleza de la cosa" rebasa, según Coing, su significación literal. No se refiere únicamente a los objetos que desempeñan algún papel en nuestra vida, sino que además incluye "por una parte, la naturaleza del hombre, sus capacidades naturales, sus impulsos, sus objetivos volitivos, etc., tal como se presentan en las diversas edades de su vi$\mathrm{da}, \mathrm{y}$, por otra parte, incluye la característica objetividad propia de los diversos ámbitos de la actividad y de las diversas comunidades del hombre" (27).

La "naturaleza de las cosas" vista como permanente ordenamiento de los seres y de los actos humanos, sirve de sustento a los criterios con que precisamos el contenido de la justicia.

Pero no basta para alcanzar la justicia, ordenar a los hombres y a los procesos sociales "por el procedimiento de adjudicarles el lugar que ya ocupan en el eterno orden del ser" (28) con lo cual la tarea del legislador justo sería una tarea científica, el derecho natural un reflejo de aquel orden, y su conocimiento facilitaría dar a cada uno lo suyo. Es necesario erigir una jerarquía moral, formada por valores, sobre los que se eleva la justicia y la dignidad personal del hombre apoyada en su libertad y bajo la guía de la "naturaleza de la cosa".

La dinámica del derecho realiza una permanente "adición o corrección de las situaciones fundamentales con intervención de la noción del valor, adición y corrección que dependen de la naturaleza de las cosas" (29).

En cuanto a los valores, éstos no se liberan sino progresivamente en el curso de la historia, gracias a la "naturaleza de las cosas" que es el elemento motor de su desarrollo dinámico.

26. Nikos Poulantzas. Nature de choses et Droit. Essai sur la dialectique du fait et de la valeur. L. G. D. I. Pgns., 1965.

27. Fundamentos de la Filosofía del Derecho. Traducción castellana de Juan Manuel Mauri. Editorial Ariel, Barcelona, 1961, pg., 131.

28. Id. pg., 134.

29. Brimo, o b. cit. pg., 398.
El existencialismo de Sartre y la influencia marxista inciden en la tesis sustentada por Nikos Poulantzas en la obra "Nature des choses et droit" que Heva el explicativo subtítulo "Essai sur la dialectique du fait et de la valeur'" (30).

Los valores son, según Poulantzas, creaciones del hombre en tanto que realiza el "proyecto libre" de su existencia. Gracias al trabajo humano, los valores penetran en las cosas, se unifican con ellas en la "naturaleza" que es fuente objetiva del derecho.

La dinámica creadora de la vida nos impulsa a una continua superación del presente en el que vamos realizando ideales y valores que incitan al desenvolvimiento del proyecto constitutivo de la existencia.

Dentro de ese "proceso dialéctico", "hecho" y "valor" significan momentos diferentes, etapas distintas y sucesivas del cambio, que debe entenderse como paso de una situación puesta a otra nueva.

El contenido del valor está constituido por la existencia auténtica del hombre que es su libertad que sólo existe en función de la libertad de otro. Tal enseñó Sartre, para quien "nuestra propia existencia no puede existir sino frente a la libertad y a la existencia de otro" (31).

La filosofía reseñada lleva en sí dos graves problemas: el del subjetivismo que se desprende de creación del valor al desarrollarse el "proyecto libre" de la existencia humana, y el de su compenetración con las cosas vigente desde Platón.

\section{Conclusiones}

La "naturaleza de las cosas" es una elaboración jurídica que puede considerarse, de acuerdo con la opinión de Bobbio, como concepción general del derecho, como fuente material del mismo y como medio de interpretación (32).

Esta teoría, nacida del anhelo de liberar al pensamiento de las exageraciones del subjetivismo para descubrir en el fondo mismo de las realidades las raices del derecho, y los más adecuados justificativos para su aplicación, conduce, sin embargo, a debatir, entre otras, las cuestiones referentes a la función que

30. Id. pg., 82 .

31. Id. pg., 128.

32. Annales, cit. pg., 222. 
desempeñan las cosas en la génesis del derecho y la construcción de un sistema normativo a través de los datos empíricos.

El primer interrogante se resuelve en las preguntas concretas por el significado de "cosa" y de "naturaleza" dentro del ámbito de la regulación racional de la conducta humana; y, el segundo, plantea el problema que se refiere a la relación entre hecho y valor, solucionado por la filosofía existencialista en favor de uno de esos fenómenos.

Debemos entender por "cosa" no un objeto o ser tomado en sentido general, sino la materia de la relación jurídica, en la que Radbruch ve "una realidad conceptual preformada" (33).

De modo análogo, "naturaleza" no significa "esencia" o "sentido" sino la nota especial que corresponde a cada cosa de acuerdo con la finalidad que persigue cada relación jurídica.

El legislador al crear la norma jurídica, y el juez al aplicarla, del mismo modo que el intérprete, deben descubrir la nota propia de los objetos que interesa al derecho en cada situación.

33. Id. pg., 73.
El sentido normativo de la "naturaleza de las cosas", no deriva de valores dotados de existencia objetiva que se piensan dentro de las reglas, ni de otros elaborados por el propio sujeto, sino de ese "contenido axiológico" que llevan consigo todos los seres.

Todos los seres buscan su perfección mediante la consecución de un bien que tiene razón de fin, según la enseñanza de Santo Tomás. El ser que complementa a otro es un bien para éste porque se adecúa a su fin. De ese modo, ser y bien se confunden (Ens et bonum convertantur).

De aqui se desprende que el bien (el valor, para expresarlo en lenguaje post-kantiano) que realizan las cosas, y, que, es a la vez, razón de las relaciones que se constituyen en base a ellas y de la normatividad que deriva, corresponde al plano del ser mismo.

El derecho es fruto de la razón especulativa y de la razón práctica del hombre. La primera es fuente de la elaboración teórica que realiza el jurista, la segunda de las regulaciones prácticas que establece el jurisprudente. Aquélla delinea las normas generales; ésta, traza los preceplos de aplicación que deben adaptarse a la "naturaleza de las cosas".

Lima, agosto de 1973. 